\title{
Bacterial Communities of Sediments in a Seawater- Freshwater Transition Zone During the Wet and Dry Seasons in Pearl River Estuary
}

\section{Yongbin Li}

National-Regional Joint Engineering Research Center for Soil Pollution Control and Remediation in South China, Guangdong Key Laboratory of Integrated Agro-environmental Pollution Control and Management, Institute of Eco-environmental and Soil Sciences, Guangdong Academy of Sciences, Guangzhou 510650, China

\section{Duanyi Huang}

National-Regional Joint Engineering Research Center for Soil Pollution Control and Remediation in South China, Guangdong Key Laboratory of Integrated Agro-environmental Pollution Control and Management, Institute of Eco-environmental and Soil Sciences, Guangdong Academy of Sciences, Guangzhou 510650, China

\section{Weimin Sun}

National-Regional Joint Engineering Research Center for Soil Pollution Control and Remediation in South China, Guangdong Key Laboratory of Integrated Agro-environmental Pollution Control and Management, Institute of Eco-environmental and Soil Sciences, Guangdong Academy of Sciences, Guangzhou 510650, China

\section{Xiaoxu Sun}

National-Regional Joint Engineering Research Center for Soil Pollution Control and Remediation in South China, Guangdong Key Laboratory of Integrated Agro-environmental Pollution Control and Management, Institute of Eco-environmental and Soil Sciences, Guangdong Academy of Sciences, Guangzhou 510650, China

\section{Gen Yan}

National-Regional Joint Engineering Research Center for Soil Pollution Control and Remediation in South China, Guangdong Key Laboratory of Integrated Agro-environmental Pollution Control and Management, Institute of Eco-environmental and Soil Sciences, Guangdong Academy of Sciences, Guangzhou 510650, China

\section{Wenlong Gao}

National-Regional Joint Engineering Research Center for Soil Pollution Control and Remediation in South China, Guangdong Key Laboratory of Integrated Agro-environmental Pollution Control and Management, Institute of Eco-environmental and Soil Sciences, Guangdong Academy of Sciences, Guangzhou 510650, China

Hanzhi Lin ( $\nabla$ hanzhi_lin@126.com ) 
National-Regional Joint Engineering Research Center for Soil Pollution Control and Remediation in South China, Guangdong Key Laboratory of Integrated Agro-environmental Pollution Control and Management, Institute of Eco-environmental and Soil Sciences, Guangdong Academy of Sciences, Guangzhou 510650, China

\section{Research Article}

Keywords: Seawater intrusion, Moraxellaceae, Planococcaceae, Keystone taxa, Rhizobium

Posted Date: June 15th, 2021

DOI: https://doi.org/10.21203/rs.3.rs-604274/v1

License: (c) (1) This work is licensed under a Creative Commons Attribution 4.0 International License. Read Full License 


\section{Abstract}

Seawater intrusion has a detrimental effect on agriculture, industry and human health. One question of particular interest is how the microbial community responds to and reflects seawater intrusion with seasonal variation. The current study explored the seasonal changes in bacterial community composition and interaction in the vicinity of Pearl River Estuary in January (dry season) and September (wet seasons). Results indicated that the salinity (expressed as electrical conductivity value) of sediment samples obtained in dry season was higher than that in wet season. The salt stress induced a declined alpha diversity but resulted in a loosely connected and unstable biotic interaction network in the bacterial communities. Random forest prediction and redundancy analysis of bacterial community indicated that salinity substantially affected the bacterial communities. Multiple lines of evidence, including the enrichment of bacterial taxa in the high-salinity location, microbe-microbe interactions, environmentmicrobe interactions, and machine learning approach, demonstrated that the families Moraxellaceae and Planococcaceae were the keystone taxa and were resistant to salt stress, which suggested that both of them can be used as potential biological indicators of monitoring and controlling seawater intrusion in coastal zone areas.

\section{Introduction}

Saltwater intrusion has become a prominent environmental concern all around the world [1]. Salt accumulation has poses exacerbated threats to local agricultural/industrial production and coastal community health around the world [2, 3]. In Netherlands, 20 well fields were closed and 9 had to lean upon artificial replenishment owing to the salinization between 1880 and 1992 [4]. In Vietnamese Mekong Delta, rice yield loss was predicted about 2.5-4.05 tons ha-1 per year due to the saltwater intrusion [5]. Moreover, saltwater intrusion caused the salinization of groundwater and agricultural soil, which resulted in increasing the risk of hypertension and cardiovascular diseases of human beings because of the high salt intake [6-8]. Currently, many countries around the world are suffering from ill effects of seawater intrusion, including France [9], America [10], Australia [11], China [12], Italy [13], Tunisia [14], the United Arab Emirates [15], Bangladesh [16]. Hence, cost-efficient strategies for monitoring and controlling seawater intrusion should be implemented to prevent freshwater quality deterioration [7].

The saltwater-freshwater transition zone has always been one of the intensive study areas in current estuarine research due to its important role in connecting terrestrial and Marine ecosystems [17]. However, majority of past studies have concentrated on the monitoring of water quality changes, the hydrodynamics of groundwater in the saltwater-invaded area, and the approaches used for the assessment and management of seawater intrusion, while only a few have addressed the response of microbial community to saltwater intrusion $[18,19]$. The dominant bacteria contain many haloresistant and halotolerant microorganisms [20,21]. These microorganisms can be used as potential indicators of saltwater intrusion [21]. Noticeably, some salt-tolerant enzymes extracted from these halophilic microorganisms performed well in a seawater system and thus have the potential to be applied as biocatalysts, which is beneficial to reduce demand for freshwater in large-scale industrial processes [22]. 
Due to seasonal changes, saltwater intrusion is influenced by drought frequency and duration [23]. Prolonged drought increases intrusion of saltwater into freshwater systems [24] and elevates the maximum salinity of high tides or streams during low flows [25]. A number of researches found that seasonal fluctuations showed prominent effects on microbial community at varied habitats [26]. Microbial community structure in marine ecosystems shifted significantly with seasonal alternations in Western English Channel [27]. The microbial community in coastal water samples collected in spring was the most diverse among all seasons, indicating the seasonal fluctuation alters the microbial community structure [28]. One recent study [29] pointed out that the microbial community composition in estuary reservoir exhibited significant seasonal variations, that is, Synechococcus was the dominant taxa in warm season, while in cold season, Actinobacteria and Bacteroidetes had higher abundances and exhibited co-occurrence patterns with salt ions. Consequently, it will be pivotal to know the seawater intrusion impacts in order to delineate the microbial spatiotemporal distributions in seawater-freshwater transition zone.

In China, the phenomenon of saltwater intrusion in the Pearl River Estuary has become more serious than ever before due to the exacerbated climate change and anthropogenic activities [30-32]. This estuary, therefore, provides excellent natural labs to investigate the effects of saltwater intrusion on microbial communities. Thus, in this study, the sediment samples were collected in January and September 2020 for physicochemical parameter analysis, genetic 16S rRNA amplicon sequencing, and multivariable statistics analysis. The aims are to i) investigate the effects of seasonal variations of seawater intrusion on the bacterial community, particularly in the biodiversity, composition, and biotic interactions, and ii) identify suitable microbial taxa as indicators for seasonal seawater intrusion variation.

\section{Materials And Methods \\ 2.1 Sample site}

This study was done in Pearl River Estuary, Guangdong Province, China. There are three sampled sites. The nearest monitoring location ( $\left.\mathrm{ZH}, 113^{\circ} 24^{\prime} 18.01^{\prime \prime}, 22^{\circ} 0^{\prime} 26.31^{\prime \prime}\right)$ away from the sea is located at the beach. The other two sampling sites are JM $\left(113^{\circ} 5^{\prime} 50.48^{\prime \prime}, 22^{\circ} 38^{\prime} 48.17^{\prime \prime}\right)$ and FS $\left(112^{\circ} 54^{\prime} 17.82^{\prime \prime}, 23^{\circ} 21^{\prime} 56.46^{\prime \prime}\right)$, which are about $85 \mathrm{~km}$ and $150 \mathrm{~km}$ away from the ZH site. The sediment samples were collected in January and September 2020, and a total of 30 samples ( 5 samples per site and time) were collected. The samples were were cryopreserved with dry ice during the transportation and stored at $-20^{\circ} \mathrm{C}$.

\subsection{Sample geochemical parameters}

Samples were freeze-dried and ground with 200-mesh sieve. The electrical conductivity (EC) and pH were measured in suspension (dry sediment/water, 1:5). Sulfate and nitrate concentrations were detected with ion chromatography (DIONEX, Sunnyvale, USA) after slurry was centrifugated at $4000 \mathrm{~g}$ for $10 \mathrm{~min}$ at room temperature. Sediment samples were analyzed for total organic carbon (TOC) with a MACRO elemental analyzer (Elementar, Hanau, Germany). 


\subsection{DNA extraction and Illumina MiSeq sequencing}

DNA was extracted using Qiagen DNeasy Powersoil kit (Dresden, Germany). The 16S rRNA gene (V4-V5 region) was amplified with 515F/806R primer pair (Caporaso et al., 2010). Amplification productions were quantified using a microplate fluorescence reader FLX800T (BioTek Instruments, Inc. Winooski, Vermont) and pooled at equimolar ratios for paired-end sequencing on Illumina MiSeq platform at Personal Biotechnology (Shanghai, China). Then, raw reads were subjected to quality checking, trimming, and chimera elimination using QIIME2 [33], and then the clean sequences were clustered by DADA2 [34]. Representative amplicon sequence variants (ASVs) were assigned against the Nucleotide Sequence Database. The obtained raw data have been committed to the database of NCBI (accession no. PRJNA731343).

\subsection{Statistical analysis}

The alpha diversity estimation and Bray-Curtis distance matrices-based principal coordinate analysis (PCoA) of microbial communities were analyzed using QIIME2. Redundancy analysis (RDA) was analyzed using the OmicStudio (https://www.omicstudio.cn/tool). Statistical analysis of data was carried out with Wilcoxon rank sum test or Student's $t$-test in SPSS v.20. Correlations between physicochemical parameters and Simpson index were analyzed using random forest (RF) algorithm [35]. The R package ggplot2 was used to visualize the RF model based on the partial dependence plots.

To gain a better understanding of potential interactions of "microbe-microbe" and "environment-microbe", co-occurrence network analysis was constructed with Gephi [36, 37]. A connected link denotes a high and significant Spearman's correlation $(|r|>0.6, p<0.05)$. Link thickness corresponds to the absolute value of Spearman's correlation coefficient, and node size corresponds to the number of connections (i.e., degree).

\section{Result}

\subsection{Physicochemical parameters}

The physicochemical parameters of samples in three locations collected in January and September were measured according standard methodology (Fig. 1). For carbonic analysis, compared to the January samples, the September samples had significantly lower EC and TOC in three locations except FS. The nitrate concentration was significantly higher in January samples than in September samples in FS. pH values fluctuated markedly, in both FS and JM, in January (slightly acidic) and September (slightly alkaline), while in $\mathrm{ZH}$, the $\mathrm{pH}$ values were fairly consistent in the two sampling points (ranging between 6.73 and 6.82). In three locations, the sulfate concentration was significantly higher in January than in September.

\subsection{Bacterial community diversity}


The bacterial community composition in the three collection sites was revealed by $16 \mathrm{~S}$ rRNA amplicon sequencing. In $\mathrm{ZH}$, the alpha diversity (including ACE, Fisher, Chao1, Shannon, Simpson, and Observed species) was higher in September than in January (Fig. 2A), demonstrating both evenness and richness were higher in September than in January. The effects of the physicochemical parameters on the Simpson index was evaluated using RF predictions (Fig. 2B). EC was the main factor, which adversely affected the alpha diversity of bacterial communities. Based on the PCOA and PERMANOVA analysis, the bacterial community compositions in different locations in January and September could be clearly separated (Fig. 2C, p <0.001). ZH had a high EC and bacterial community with great changes and thus we mainly focused on the bacterial community in $\mathrm{ZH}$ in the subsequent section.

\subsection{Composition of bacterial community}

The above results showed important insights into how diversity of bacterial community responds to physicochemical parameters at general community level. Subsequently, the response of individual taxa at different levels to physicochemical parameters was further investigated. At phylum level, the abundance of Proteobacteria ranked first among all samples, accounting for $27.0-62.7 \%$ of the whole bacterial community, followed by Acidobacteria, Chloroflexi, Firmicutes, Actinobacteria, Bacteroidetes, Planctomycetes, Nitrospirae, and Gemmatimonadetes (Fig. 3A). Specifically in ZH, Proteobacteria and Firmicutes were significantly enriched in January, while Acidobacteria, Chloroflexi, Bacteroidetes, Planctomycetes, and Gemmatimonadetes were significantly enriched in September (Fig. S1). Further analysis at family level were performed and revealed enrichment of distinct bacterial taxa in January and September (Fig. 3B). Some bacteria, including Moraxellaceae, Planococcaceae, Anaerolineaceae, Syntrophaceae, Gaiellaceae, Micrococcaceae, were significantly enriched in January samples, while Thermoanaerobaculaceae, Gemmatimonadaceae, Saprospiraceae were enriched in September samples in ZH (Fig. S2).

\subsection{Interaction networks and distinct keystone taxa}

The microbe-microbe interactions (biotic interaction) were predicted (three in January and three in September) using the interactive platform Gephi (Fig. 4A). The biotic interaction in January showed 1951 nodes and 36-178 strong and significant connections (links). However, in September, the biotic interactions were more complicated, containing 40-56 nodes and 121-243 links (Fig. 4B). The results demonstrated that the potential interactions were weaker in January than in September, especially in ZH. Additionally, the ratio of positive link number to negative link number in each network was calculated. Expect for January samples in $\mathrm{ZH}$, the ratios from other samples remained $\sim 68 \%$. However, in January samples in $\mathrm{ZH}$, the proportion of positive link was much higher than that of negative link as a result of the reduced proportion of negative links. The keystone taxa were identified according to the standard of the nodes with low betweenness centralities and high degrees [38, 39]. In January samples in ZH, a total of sixteen ASVs were defined as keystone taxa (Table S1), which were further assigned to Moraxellaceae (eight ASVs) and Planococcaceae (eight ASVs) at family level. 
The environment-microbe interactions in January samples in $\mathrm{ZH}$ further demonstrated that $\mathrm{EC}$ was the main factor, which influenced 16 individual ASVs (Spearman $>|0.6|$ and $p<0.05$ ) (Fig. 5). The predominant influence of EC in ZH was also supported by RDA analysis (Fig. 6), and by the bacterial diversity result in Sect. 3.2. Other physicochemical parameters, including sulfate, TOC, and nitrate, also had great influences on the community composition. Importantly, all identified sixteen keystone taxa were also detected in this environment-microbe network, and all of them exhibited positive correlations with EC (Tables S2, S3).

RF analysis indicated that EC was the main factor influencing the relative abundances of Moraxellaceae and Planococcaceae (Fig. 7). Indeed, Moraxellaceae and Planococcaceae had high relative abundances within a certain range of EC value (e.g., EC > $1650 \mathrm{us} \mathrm{cm}^{-1}$ ), indicating that Moraxellaceae and Planococcaceae could be halotolerant and/or halophilic bacteria.

\section{Discussion}

Seawater intrusion is a universal environmental issue, esp. under the current scenario of exacerbated climate change and human activities. However, to date, studies focused on the response of the microbial community to saltwater intrusion was still scarce, though the application of microorganisms to monitor and control seawater intrusion is being widely considered as an effective and economical strategy. In this study, we selected three sampled places in Pearl River Estuary suffering from varying degrees of seawater intrusion, and collected the sediment in January and September 2020, respectively. Aims of this research were to investigate the influences of saltwater intrusion on bacterial communities and detect some potential microbial indicators for seawater intrusion.

\subsection{Diversity and composition of bacterial community}

In JM and ZH, the January samples showed higher EC values than September samples (Fig. 1), which suggested that seawater intrusion was aggravated during dry season (January). Owing to heavy rainfall during monsoon season (represented by September samples), the recharge rates were considerably high in most coastal aquifers with a high groundwater table, which raises the freshwater level in coastal aquifers and restricts intrusion of seawater [7,40]. Environmental stresses including salt stress are considered as major drivers of microbial community diversity $[41,42]$. In this study, bacterial community alpha diversity was lower in January than in September in $\mathrm{ZH}$, suggesting an inverse relationship between salinity and diversity of bacterial community (Fig. 2). Similarly, the alpha diversity was lower in seawater than in irrigation water and groundwater [43]. RF analysis further demonstrated that EC exerted adverse effects on alpha diversity (Fig. 2B). The effects of salinity on microbial community diversity is mainly due to the alternation of plasma membrane, especially the solute contents which plays a vital role in water fluxes regulation [44]. An increase in salinity would lead to water efflux and dehydration, while a decrease in salinity cells would induce water influx of high solute contents, cell swelling and eventually resulted in cell lysis [45].

\subsection{Microbial interaction networks}


Network analysis has been increasingly used as a critical tool for exploring microbial community symbiosis patterns in ecosystem studies [46, 47]. In this study, salt stress suppressed the potential interactions within microbial communities, especially in ZH (Fig. 4). This can be interpreted with the deleterious effects of high salinity on microbial growth due to ionic, osmotic and oxidative stresses [48]. Salt stress made the nodes dispersed and loosely linked in the bacterial interaction networks [49]. When a microbial community possessing a large percentage of members linked together through positive correlation, it tends to be unstable. This is because in such a community, members are likely to react uniformly to circumstantial fluctuations, giving rise to a positive feedback and resonance. On the contrary, negative links are likely to stabilize the resonance of such communities and thus contribute to the stability of the network [50]. Therefore, the study suggested that salt stress suppressed network potential interactions and affected the network stability.

\subsection{Moraxellaceae and Planococcaceae as the keystone taxa}

Generally, keystone taxa are considered part of the core microbial communities [51, 52]. These keystone taxa significantly influence material transformation, energy metabolism, and/or nutrient cycling in response to geochemical and biological factors because they can choose different environmentdependent survival strategies to develop the whole microbial communities in their favor [53-55], and the absence of these keystone taxa can potentially cause tremendous shifts in the composition and function of the microbial communities $[56,57]$. Usually, the keystone taxa were identified according to the criteria of high degree nodes and low betweenness $[38,39]$. In current study, Moraxellaceae and Planococcaceae were identified as the keystone bacteria based on multiple pieces of evidence, and they had positive correlations with EC (Figs. 6,7). It suggested that the identified keystone bacteria may be resistant to salinity. In fact, some members of Moraxellaceae and Planococcaceae have been isolated from various hypersaline habitats [58-61].

In this study, Psychrobacter and Acinetobacter belonging to Moraxellaceae family were detected. Psychrobacter could survive in extremely cold habitats, such as in ice, soil, sediments in Antarctic, as well as in deep sea environments [58]. This finding is consistent with our result that Psychrobacter was enriched in January when low temperature condition existed. Besides, some strains of Psychrobacter have been isolated and/or detected in variety of hypersaline surroundings [59, 62-64]. Psychrobacter sp. ANT206 was isolated from Antarctic sea-ice, which not only had high catalytic efficiency at low temperatures but also displayed remarkable salt tolerance [59]. Psychrobacter was identified as the predominant bacterium at high salinity $\left(15 \mathrm{~g} \mathrm{~L}^{-1} \mathrm{NaCl}\right)$ [65]. The another genus Acinetobacter belonging to Moraxellaceae were also reported to tolerant to salt stress [66-68].

Some genus belonging to the family Planococcaceae have been isolated in variety of hypersaline surroundings $[60,61,69]$. For example, the xylanase from Planococcus sp. SL4 which was obtained from the sediment in soda lake Dabusu was found to be salt-tolerant, showing great prospect of basic research and industrial applications [60]. Similarly, Planomicrobium and Planococcus halotolerans could grow 
optimally under conditions with high salinity $[61,70]$. Therefore, these results further suggested that keystone Planococcaceae identified in this study could be resistant to salinity.

\subsection{Bacterial community application in seawater intrusion}

Diverse microorganisms have previously been found in the sediment [71, 72]. Microorganisms are highly sensitive to pollutants, and this character makes them frequently applied as potential ecological indicators to diagnose environmental pollutions, such as organic contaminations [73] and heavy metal(loid) contaminations [74-76]. However, there is still a paucity on the application of microbial analysis in the study of seawater intrusion. Since seawater is regarded as a pollutant in the context of seawater intrusion, it seems logical and significant to adopt microbes as biological indicators to evaluate the seawater intrusion.

In this study, it is apparently showed that seawater intrusion changed the diversity, composition, and microbe-microbe interactions of microbial communities. The keystone taxa were recognized in the place with high salinity. The results of this study can provide a reference for exploring new microbial indicators of seawater intrusion. For example, seasonal variations in microbial interactions could be applied to characterize the degree of seawater intrusion [7]. Order Oceanospirillales and family Alteromonadaceae have already been suggested as indicators of seawater intrusion [43]. But more detailed microbial analyses with the variation of seawater intrusion need to be conducted, which will pave the way for rational seawater intrusion monitoring and management.

\section{Conclusion}

In this study, the Pearl River Estuary was selected to investigate the microbial adaption and response to seawater intrusion. Compared to the September (wet seasons) samples, the January (dry season) samples had higher salinity. In ZH, salt stress significantly affected alpha diversity and composition of bacterial communities. The nodes in microbe-microbe networks were loosely connected in the high salinity sediment, while they were densely interconnected in the low salinity samples. Besides, salt stress reduced the stability of the microbial community. In this study, based on multiple lines of evidence, members of Moraxellaceae and Planococcaceae were regarded as the keystone taxa and were resistant to salinity. Therefore, the microbial family Moraxellaceae and Planococcaceae may be used as biological indicators of seawater intrusion.

\section{Declarations}

\section{Acknowledgements}

This work was supported by the Science and Technology Planning Project of Guangzhou (Grant Nos. 202002020072 and 201904010366), the National Natural Science Foundation of China (Grant No. 41771301), GDAS' Project of Science and Technology Development (Grant Nos. 2021GDASYL20210103048, 2020GDASYL-20200102015, 2019GDASYL-0102002-4 and 2019GDASYL-0102002-1), 
Guangdong Basic and Applied Basic Research Foundation (Grant No. 2021A1515011374 and 2021A1515011461), the National Natural Science Foundation of China (Grant No. U20A20109), the Science and Technology Planning Project of Guangdong Province (Grant No. 2019B110210003), and Guangdong Introducing Innovative and Entrepreneurial Talents (Grant No. 2017GC010570).

\section{Compliance with ethical standards}

Ethical approval Not applicable.

Consent to participate Not applicable.

Consent to publish Not applicable.

Data availability All data related to this publication are made available from the corresponding author on reasonable request.

Competing interests The authors declare that they have no conflict of interest.

\section{References}

1. Klassen J, Allen DM (2017) Assessing the risk of saltwater intrusion in coastal aquifers. Journal of Hydrology 551: 730-745. doi: https://doi.org/10.1016/j.jhydrol.2017.02.044

2. Kazakis N, A P, Vargemezis G, G S, Pliakas F-K (2016) Seawater intrusion mapping using electrical resistivity tomography and hydrochemical data. An application in the coastal area of eastern Thermaikos Gulf, Greece. Science of The Total Environment 543: 373-387. doi: 10.1016/j.scitotenv.2015.11.041

3. Dam THT, Amjath-Babu TS, Zander P, Müller K (2019) Paddy in saline water: Analysing varietyspecific effects of saline water intrusion on the technical efficiency of rice production in Vietnam. Outlook on Agriculture 48: 237-245. doi: 10.1177/0030727019850841

4. Stuyfzand PJ, Maas K, Kappelhof J, Kooiman JW (2004) Pumping brackish groundwater to prepare drinking water and keep salinized wells fresh. 18th Salt Water Intrusion Meeting, Cartagena, Spain, vol. 127.

5. Khat HV, Dang NH, Yabe M (2018) Impact of salinity intrusion on rice productivity in the Vietnamese Mekong Delta. Journal of the Faculty of Agriculture, Kyushu University 63: 143-148.

6. Hoque M, Scheelbeek P, Vineis P, Khan A, Ahmed KM, Butler A (2016) Drinking water vulnerability to climate change and alternatives for adaptation in coastal South and South East Asia. Climatic Change 136. doi: $10.1007 /$ s10584-016-1617-1 
7. Chen L, Zhang J, Dai H, Hu BX, Tong J, Gui D, Zhang X, Xia C (2020) Comparison of the groundwater microbial community in a salt-freshwater mixing zone during the dry and wet seasons. Journal of Environmental Management 271: 110969. doi: https://doi.org/10.1016/j.jenvman.2020.110969

8. Shammi M, Rahman MM, Bondad SE, Bodrud-Doza M (2019) Impacts of salinity intrusion in community health: A review of experiences on drinking water sodium from coastal areas of Bangladesh. Healthcare 7. doi: 10.3390/healthcare7010050

9. Petelet E, Négrel P, Aunay B, Ladouche B, Bailly-Comte V, Guerrot C, Flehoc C, Pezard P, Lofi J, Dörfliger N (2016) Coastal groundwater salinization: Focus on the vertical variability in a multi-layered aquifer through a multi-isotope fingerprinting (Roussillon Basin, France). Sci Total Environ 566-567: 398-415. doi: 10.1016/j.scitotenv.2016.05.016

10. Chaudhuri S, Ale S (2013) Temporal evolution of depth-stratified groundwater salinity in municipal wells in the major aquifers in Texas, USA. The Science of the total environment 472C: 370-380. doi: 10.1016/j.scitotenv.2013.10.120

11. Costall AR, Harris BD, Teo B, Schaa R, Wagner FM, Pigois JP (2020) Groundwater throughflow and seawater intrusion in high quality coastal aquifers. Sci Rep 10: 9866. doi: 10.1038/s41598-020-66516-6

12. Zhang W, Chen X, Tan H, Zhang Y, Cao J (2015) Geochemical and isotopic data for restricting seawater intrusion and groundwater circulation in a series of typical volcanic islands in the South China Sea. Marine Pollution Bulletin 93. doi: 10.1016/j.marpolbul.2015.01.024

13. Tiwari AK, Pisciotta A, De Maio M (2019) Evaluation of groundwater salinization and pollution level on Favignana Island, Italy. Environ Pollut 249: 969-981. doi: 10.1016/j.envpol.2019.03.016

14. Zghibi A, Mirchi A, Zouhri L, Taupin JD, Chekirbane A, Tarhouni J (2019) Implications of groundwater development and seawater intrusion for sustainability of a Mediterranean coastal aquifer in Tunisia. Environ Monit Assess 191: 696. doi: 10.1007/s10661-019-7866-5

15. Sherif M, Kacimov A, Javadi A, Ebraheem AA (2012) Modeling groundwater flow and seawater intrusion in the coastal aquifer of wadi ham, UAE. Water Resources Management 26: 751-774. doi: 10.1007/s11269-011-9943-6

16. Ahmed A, Ghosh PK, Hasan M, Rahman A (2020) Surface and groundwater quality assessment and identification of hydrochemical characteristics of a south-western coastal area of Bangladesh. Environ Monit Assess 192: 258. doi: 10.1007/s10661-020-8227-0

17. Slomp CP, Van Cappellen $P$ (2004) Nutrient inputs to the coastal ocean through submarine groundwater discharge: Controls and potential impact. Journal of Hydrology 295: 64-86. doi: 10.1016/j.jhydrol.2004.02.018 
18. Kumar V, Paranjpe J, Gosavi S, Kulkarni R, Gosavi R (2015) A Comparison of three drug combinations for sedation during middle ear surgeries under local Anesthesia: A multicentric randomized double blind study. Journal of Krishna Institute of Medical Sciences University 4: 32-40.

19. Ferchichi H, Ben Hamouda M, Farhat B, Ben Mammou A (2018) Assessment of groundwater salinity using GIS and multivariate statistics in a coastal Mediterranean aquifer. International Journal of Environmental Science and Technology 15. doi: 10.1007/s13762-018-1767-y

20. Oren A (2002) Diversity of halophilic microorganisms: Environments, phylogeny, physiology, and applications. Journal of Industrial Microbiology \& Biotechnology 28: 56-63. doi: 10.1038/sj/jim/7000176

21. Arora S, Patel PN, Vanza MJ, Rao GG (2014) Isolation and characterization of endophytic bacteria colonizing halophyte and other salt tolerant plant species from coastal Gujarat. Afr J Microbiol Res 8: 1779-1788. doi: 10.5897/AJMR2013.5557

22. Kelly SA, Moody TS, Gilmore BF (2019) Biocatalysis in seawater: Investigating a halotolerant $\omega$ transaminase capable of converting furfural in a seawater reaction medium. Engineering in Life Sciences 19: 721-725. doi: https://doi.org/10.1002/elsc.201900053

23. Heiss J, Michael H (2014) Saltwater-freshwater mixing dynamics in a sandy beach aquifer over tidal, spring-neap, and seasonal cycles. Water Resources Research 50. doi: 10.1002/2014WR015574

24. Ardon M, Morse J, Colman B, Bernhardt E (2013) Drought-induced saltwater incursion leads to increased wetland nitrogen export. Global Change Biology 19. doi: 10.1111/gcb.12287

25. Neubauer S, Craft C (2009) Global change and tidal freshwater wetlands: Scenarios and impacts. In: A, B, DF, W, AH, B (eds.), Tidal Freshwater Wetlands, pp. 253-266

26. Zheng T, Deng Y, Wang Y, Jiang H, O'Loughlin EJ, Flynn TM, Gan Y, Ma T (2019) Seasonal microbial variation accounts for arsenic dynamics in shallow alluvial aquifer systems. Journal of Hazardous Materials 367: 109-119. doi: https://doi.org/10.1016/j.jhazmat.2018.12.087

27. Jack G, Dawn F, Swift P, Newbold L, Oliver A, Smyth T, Somerfield P, Huse S, Joint I (2009) The seasonal structure of microbial communities in the Western English Channel. Environmental Microbiology 11: 3132-3139. doi: 10.1111/j.1462-2920.2009.02017.x

28. Patel $\mathrm{V}$, Munot $\mathrm{H}$, Shouche $\mathrm{Y}$, Madamwar $\mathrm{D}$ (2014) Response of bacterial community structure to seasonal fluctuation and anthropogenic pollution on coastal water of Alang-Sosiya ship breaking yard, Bhavnagar, India. Bioresource Technology 161C: 362-370. doi: 10.1016/j.biortech.2014.03.033

29. Xu Z, Woodhouse JN, Te SH, Yew-Hoong Gin K, He Y, Xu C, Chen L (2018) Seasonal variation in the bacterial community composition of a large estuarine reservoir and response to cyanobacterial proliferation. Chemosphere 202: 576-585. doi: https://doi.org/10.1016/j.chemosphere.2018.03.037 
30. Wang Y, Jiao JJ (2012) Origin of groundwater salinity and hydrogeochemical processes in the confined Quaternary aquifer of the Pearl River Delta, China. Journal of Hydrology 438-439: 112-124. doi: https://doi.org/10.1016/j.jhydrol.2012.03.008

31. Zhou W, Luo L, Xu H, Wang D (2012) Saltwater intrusion in the Pearl River Estuary during winter. Aquatic Ecosystem Health \& Management 15: 70-80. doi: 10.1080/14634988.2012.649238

32. Li (2020) Saltwater intrusion in the Pearl River Estuary (China): Variation characteristics and cause analysis. Journal of Coastal Research 36. doi: 10.2112/JCOASTRES-D-19-00130.1

33. Bolyen E, Rideout JR, Dillon MR, Bokulich NA, Abnet CC, Al-Ghalith GA, Alexander H, Alm EJ, Arumugam M, Asnicar F, Bai Y, Bisanz JE, Bittinger K, Brejnrod A, Brislawn CJ, Brown CT, Callahan BJ, Caraballo-Rodríguez AM, Chase J, Cope EK, Da Silva R, Diener C, Dorrestein PC, Douglas GM, Durall DM, Duvallet C, Edwardson CF, Ernst M, Estaki M, Fouquier J, Gauglitz JM, Gibbons SM, Gibson DL, Gonzalez A, Gorlick K, Guo J, Hillmann B, Holmes S, Holste H, Huttenhower C, Huttley GA, Janssen S, Jarmusch AK, Jiang L, Kaehler BD, Kang KB, Keefe CR, Keim P, Kelley ST, Knights D, Koester I, Kosciolek T, Kreps J, Langille MGI, Lee J, Ley R, Liu Y-X, Loftfield E, Lozupone C, Maher M, Marotz C, Martin BD, McDonald D, Mclver LJ, Melnik AV, Metcalf JL, Morgan SC, Morton JT, Naimey AT, Navas-Molina JA, Nothias LF, Orchanian SB, Pearson T, Peoples SL, Petras D, Preuss ML, Pruesse E, Rasmussen LB, Rivers A, Robeson MS, Rosenthal P, Segata N, Shaffer M, Shiffer A, Sinha R, Song SJ, Spear JR, Swafford AD, Thompson LR, Torres PJ, Trinh P, Tripathi A, Turnbaugh PJ, Ul-Hasan S, van der Hooft JJJ, Vargas F, Vázquez-Baeza Y, Vogtmann E, von Hippel M, Walters W, Wan Y, Wang M, Warren J, Weber KC, Williamson CHD, Willis AD, Xu ZZ, Zaneveld JR, Zhang Y, Zhu Q, Knight R, Caporaso JG (2019) Reproducible, interactive, scalable and extensible microbiome data science using QIIME 2. Nature Biotechnology 37: 852-857. doi:

10.1038/s41587-019-0209-9

34. Callahan BJ, McMurdie PJ, Rosen MJ, Han AW, Johnson AJ, Holmes SP (2016) DADA2: Highresolution sample inference from Illumina amplicon data. Nat Methods 13: 581-583. doi: 10.1038/nmeth.3869

35. Wang Q, Xie Z, Li F (2015) Using ensemble models to identify and apportion heavy metal pollution sources in agricultural soils on a local scale. Environmental Pollution 206: 227-235. doi: 10.1016/j.envpol.2015.06.040

36. Banerjee S, Schlaeppi K, Van der Heijden M (2018) Keystone taxa as drivers of microbiome structure and functioning. Nature Reviews Microbiology 16: 1. doi: 10.1038/s41579-018-0024-1

37. Newman MEJ (2006) Modularity and community structure in networks. Proceedings of the National Academy of Sciences 103: 8577. doi: 10.1073/pnas.0601602103

38. Hu A, Ju F, Hou L, Li J, Yang X, Wang H, Mulla SI, Sun Q, Bürgmann H, Yu C-P (2017) Strong impact of anthropogenic contamination on the co-occurrence patterns of a riverine microbial community. Environmental Microbiology 19: 4993-5009. doi: https://doi.org/10.1111/1462-2920.13942 
39. Sun X, Xu R, Dong Y, Li F, Tao W, Kong T, Zhang M, Qiu L, Wang X, Sun W (2020) Investigation of the ecological roles of putative keystone taxa during tailing revegetation. Environ Sci Technol 54: 1125811270. doi: 10.1021/acs.est.0c03031

40. Sylus KJ, Ramesh H (2015) The study of sea water intrusion in coastal aquifer by electrical conductivity and total dissolved solid method in gurpur and netravathi river basin. Aquatic Procedia 4: 5764. doi: https://doi.org/10.1016/j.aqpro.2015.02.009

41. Peng J, Wegner CE, Liesack W (2017) Short-term exposure of paddy soil microbial communities to salt stress triggers different transcriptional responses of key taxonomic groups. Front Microbiol 8: 400. doi: $10.3389 /$ fmicb. 2017.00400

42. Lozupone CA, Knight R (2007) Global patterns in bacterial diversity. Proc Natl Acad Sci U S A 104: 11436-11440. doi: 10.1073/pnas.0611525104

43. Chen L, Hu BX, Dai H, Zhang X, Xia CA, Zhang J (2019) Characterizing microbial diversity and community composition of groundwater in a salt-freshwater transition zone. Sci Total Environ 678: 574584. doi: 10.1016/j.scitotenv.2019.05.017

44. Atashgahi S, Sánchez-Andrea I, Heipieper HJ, van der Meer JR, Stams AJM, Smidt H (2018) Prospects for harnessing biocide resistance for bioremediation and detoxification. Science 360: 743. doi: 10.1126/science.aar3778

45. Cao Y, Zhang B, Zhu Z, Song X, Cai Q, Chen B, Dong G, Ye X (2020) Microbial eco-physiological strategies for salinity-mediated crude oil biodegradation. Science of The Total Environment 727: 138723. doi: https://doi.org/10.1016/j.scitotenv.2020.138723

46. Li Y, Wang M, Chen S (2021) Application of N2-fixing Paenibacillus triticisoli BJ-18 changes the compositions and functions of the bacterial, diazotrophic, and fungal microbiomes in the rhizosphere and root/shoot endosphere of wheat under field conditions. Biology and Fertility of Soils. doi: 10.1007/s00374-020-01528-y

47. Li Y, Li Q, Chen S (2021) Diazotroph Paenibacillus triticisoli BJ-18 drives the variation in bacterial, diazotrophic and fungal communities in the rhizosphere and root/shoot endosphere of maize. International Journal of Molecular Sciences 22. doi: 10.3390/ijms22031460

48. Cui J, Sun T, Chen L, Zhang W (2020) Engineering salt tolerance of photosynthetic cyanobacteria for seawater utilization. Biotechnology Advances 43: 107578.

doi: https://doi.org/10.1016/j.biotechadv.2020.107578

49. Benidire L, El Khalloufi F, Oufdou K, Barakat M, Tulumello J, Ortet P, Heulin T, Achouak W (2020) Phytobeneficial bacteria improve saline stress tolerance in Vicia faba and modulate microbial interaction network. Sci Total Environ 729: 139020. doi: 10.1016/j.scitotenv.2020.139020 
50. Coyte K, Schluter J, Foster K (2015) The ecology of the microbiome: Networks, competition, and stability. Science 350: 663-666. doi: 10.1126/science.aad2602

51. Cordero OX, Datta MS (2016) Microbial interactions and community assembly at microscales. Curr Opin Microbiol 31: 227-234. doi: 10.1016/j.mib.2016.03.015

52. Kong T, Lin H, Xiao E, Xiao T, Gao P, Li B, Xu F, Qiu L, Wang X, Sun X, Sun W (2021) Investigation of the antimony fractions and indigenous microbiota in aerobic and anaerobic rice paddies. Science of The Total Environment: 145408. doi: https://doi.org/10.1016/j.scitotenv.2021.145408

53. Agler MT, Ruhe J, Kroll S, Morhenn C, Kim ST, Weigel D, Kemen EM (2016) Microbial hub taxa link host and abiotic factors to plant microbiome variation. PLoS Biol 14: e1002352. doi:

10.1371/journal.pbio.1002352

54. Banerjee S, Schlaeppi K, van der Heijden MGA (2018) Keystone taxa as drivers of microbiome structure and functioning. Nat Rev Microbiol 16: 567-576. doi: 10.1038/s41579-018-0024-1

55. Xun W, Huang T, Li W, Ren Y, Xiong W, Ran W, Li D, Shen Q, Zhang R (2017) Alteration of soil bacterial interaction networks driven by different long-term fertilization management practices in the red soil of South China.

56. van der Heijden MG, Hartmann M (2016) Networking in the plant microbiome. PLoS Biol 14: e1002378. doi: 10.1371/journal.pbio.1002378

57. Dunne JA, Williams RJ, Martinez ND (2002) Network structure and biodiversity loss in food webs: robustness increases with connectance. Ecology Letters 5: 558-567. doi: https://doi.org/10.1046/j.14610248.2002.00354.x

58. Dias LM, Folador ARC, Oliveira AM, Ramos RTJ, Silva A, Baraúna RA (2018) Genomic architecture of the two cold-adapted genera Exiguobacterium and Psychrobacter. Evidence of functional reduction in the Exiguobacterium antarcticum B7 genome. Genome Biology and Evolution 10: 731-741. doi: 10.1093/gbe/evy029

59. Wang Y, Hou Y, Nie P, Wang Y, Ren X, Wei Q, Wang Q (2019) A novel cold-adapted and salt-tolerant RNase R from Antarctic sea-ice bacterium Psychrobacter sp. ANT206. Molecules 24. doi: $10.3390 /$ molecules 24122229

60. Huang X, Lin J, Ye X, Wang G (2015) Molecular characterization of a thermophilic and salt- and alkaline-tolerant xylanase from Planococcus sp. SL4, a strain isolated from the sediment of a Soda Lake. J Microbiol Biotechnol 25: 662-671. doi: 10.4014/jmb.1408.08062

61. Romano I, Giordano A, Lama L, Nicolaus B, Gambacorta A (2003) Planococcus rifietensis sp. nov, isolated from algal mat collected from a sulfurous spring in Campania (Italy). Syst Appl Microbiol 26: 357-366. doi: 10.1078/072320203322497383 
62. Wang Y, Wang Q, Hou Y (2020) A new cold-adapted and salt-tolerant glutathione reductase from Antarctic psychrophilic bacterium Psychrobactersp. and its resistance to oxidation. Int J Mol Sci 21. doi: 10.3390/ijms21020420

63. Bjørkevoll I, Olsen RL, Skjerdal OT (2003) Origin and spoilage potential of the microbiota dominating genus Psychrobacter in sterile rehydrated salt-cured and dried salt-cured cod (Gadus morhua). Int J Food Microbiol 84: 175-187. doi: 10.1016/s0168-1605(02)00418-x

64. Azevedo JS, Correia A, Henriques I (2013) Molecular analysis of the diversity of genus Psychrobacter present within a temperate estuary. FEMS Microbiol Ecol 84: 451-460. doi: 10.1111/15746941.12075

65. Wang $X$, Yang T, Lin B, Tang Y (2017) Effects of salinity on the performance, microbial community, and functional proteins in an aerobic granular sludge system. Chemosphere 184: 1241-1249. doi: 10.1016/j.chemosphere.2017.06.047

66. Scholz A, Stahl J, de Berardinis V, Müller V, Averhoff B (2016) Osmotic stress response in Acinetobacter baylyi: identification of a glycine-betaine biosynthesis pathway and regulation of osmoadaptive choline uptake and glycine-betaine synthesis through a choline-responsive Betl repressor. Environ Microbiol Rep 8: 316-322. doi: 10.1111/1758-2229.12382

67. Sand M, Mingote Al, Santos H, Müller V, Averhoff B (2013) Mannitol, a compatible solute synthesized by Acinetobacter baylyi in a two-step pathway including a salt-induced and salt-dependent mannitol-1phosphate dehydrogenase. Environ Microbiol 15: 2187-2197. doi: 10.1111/1462-2920.12090

68. Sand M, de Berardinis V, Mingote A, Santos H, Göttig S, Müller V, Averhoff B (2011) Salt adaptation in Acinetobacter baylyi: identification and characterization of a secondary glycine betaine transporter. Arch Microbiol 193: 723-730. doi: 10.1007/s00203-011-0713-x

69. Dai X, Wang Y-N, Wang B-J, Liu S-J, Zhou Y-G (2005) Planomicrobium chinense sp. nov., isolated from coastal sediment, and transfer of Planococcus psychrophilus and Planococcus alkanoclasticus to Planomicrobium as Planomicrobium psychrophilum comb. nov. and Planomicrobium alkanoclasticum comb. nov. International Journal of Systematic and Evolutionary Microbiology 55: 699-702. doi: https://doi.org/10.1099/ijs.0.63340-0

70. Gan L, Li X, Tian Y, Peng B (2020) Genomic insights into the salt tolerance and cold adaptation of Planococcus halotolerans SCU63(T). Arch Microbiol 202: 2841-2847. doi: 10.1007/s00203-020-01979-9

71. Sinsabaugh RL, Hill BH, Follstad Shah JJ (2010) Erratum: Ecoenzymatic stoichiometry of microbial organic nutrient acquisition in soil and sediment. Nature 468: 122-122. doi: 10.1038/nature09548

72. Lomstein BA, Langerhuus AT, D'Hondt S, Jørgensen BB, Spivack AJ (2012) Endospore abundance, microbial growth and necromass turnover in deep sub-seafloor sediment. Nature 484: 101-104. doi: 
73. Maliszewska-Kordybach B, Klimkowicz-Pawlas A, Smreczak B (2007) Ecotoxic effect of phenanthrene on nitrifying bacteria in soils of different properties. Journal of Environmental Quality 36: 1635-1645. doi: 10.2134/jeq2007.0118

74. Sun W, Sun X, Li B, Xu R, Young LY, Dong Y, Zhang M, Kong T, Xiao E, Wang Q (2020) Bacterial response to sharp geochemical gradients caused by acid mine drainage intrusion in a terrace: Relevance of C, N, and S cycling and metal resistance. Environment International 138: 105601. doi: https://doi.org/10.1016/j.envint.2020.105601

75. Sun X, Kong T, Xu R, Li B, Sun W (2020) Comparative characterization of microbial communities that inhabit arsenic-rich and antimony-rich contaminated sites: Responses to two different contamination conditions. Environmental Pollution 260: 114052. doi: 10.1016/j.envpol.2020.114052

76. Li Y, Zhang M, Xu R, Lin H, Sun X, Xu F, Gao P, Kong T, Xiao E, Yang N, Sun W (2021) Arsenic and antimony co-contamination influences on soil microbial community composition and functions: Relevance to arsenic resistance and carbon, nitrogen, and sulfur cycling. Environment International 153: 106522. doi: https://doi.org/10.1016/j.envint.2021.106522

\section{Figures}




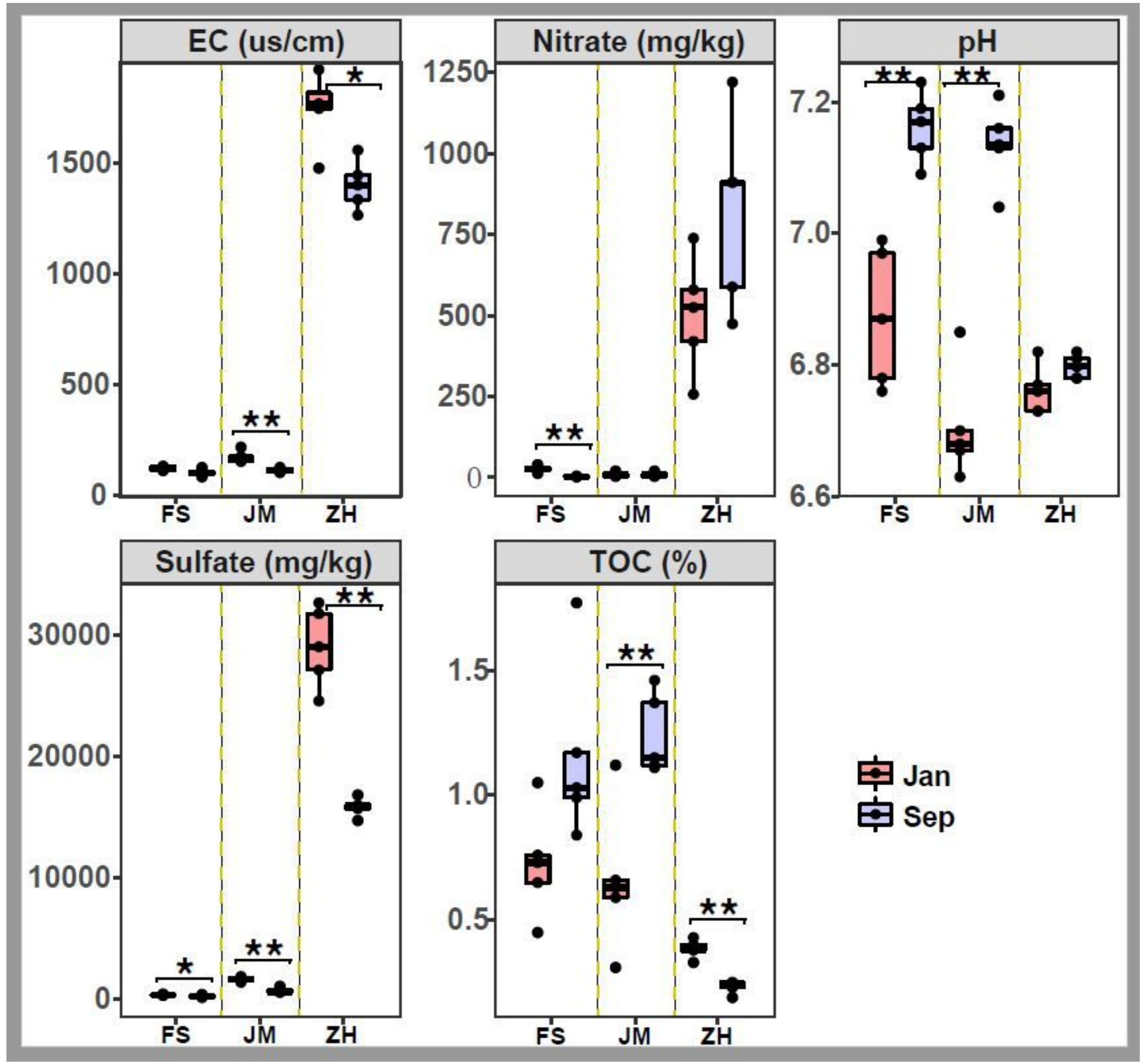

Figure 1

Physicochemical parameters of sediment samples. * and $* *$ indicate significant differences at $p<0.05$ and $p<0.01$, respectively. 


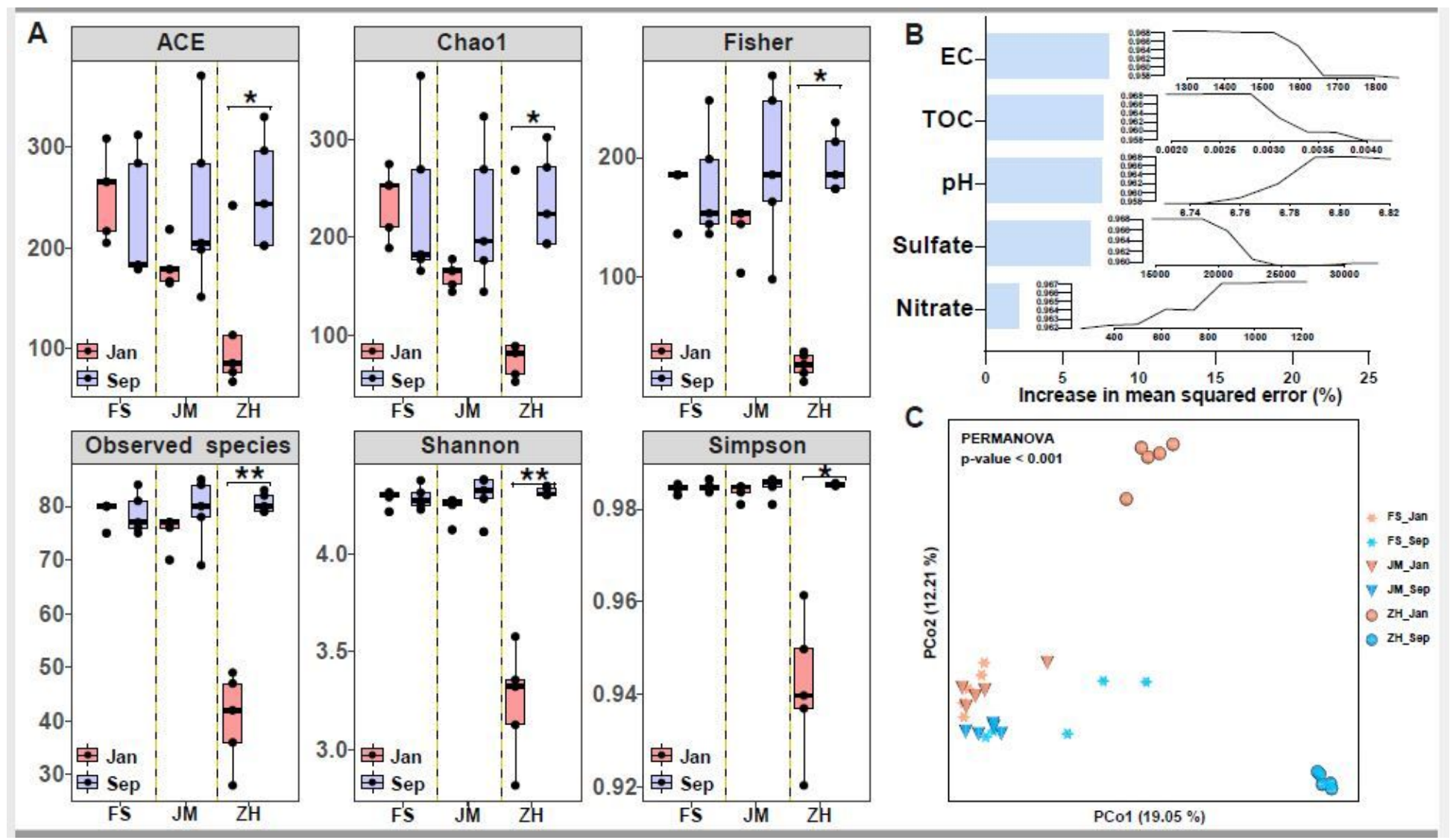

Figure 2

The diversity indices (A); random forest prediction of the relationships between physicochemical parameters and the diversity indices in ZH (B); the PCoA analysis based on the Bray-Curtis distance (C). * and $* *$ indicate significant differences at $p<0.05$ and $p<0.01$, respectively. The insert in the RF model represents the partial dependence plots revealing the dependencies of the diversity indices on the physicochemical parameters. 


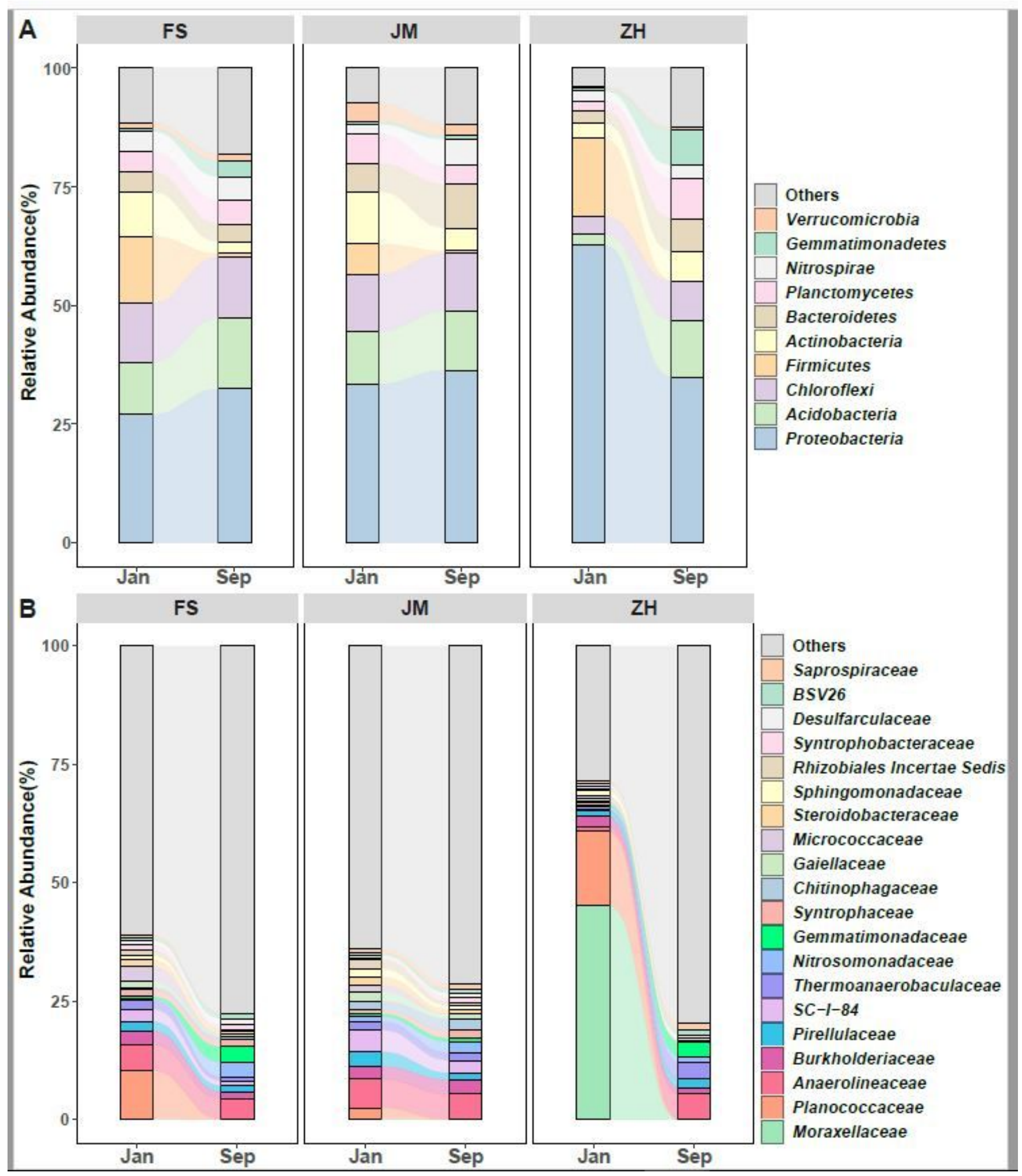

Figure 3

The relative abundances at the phylum (A) and genus (B) level based on the 16s rRNA amplicon sequencing. 


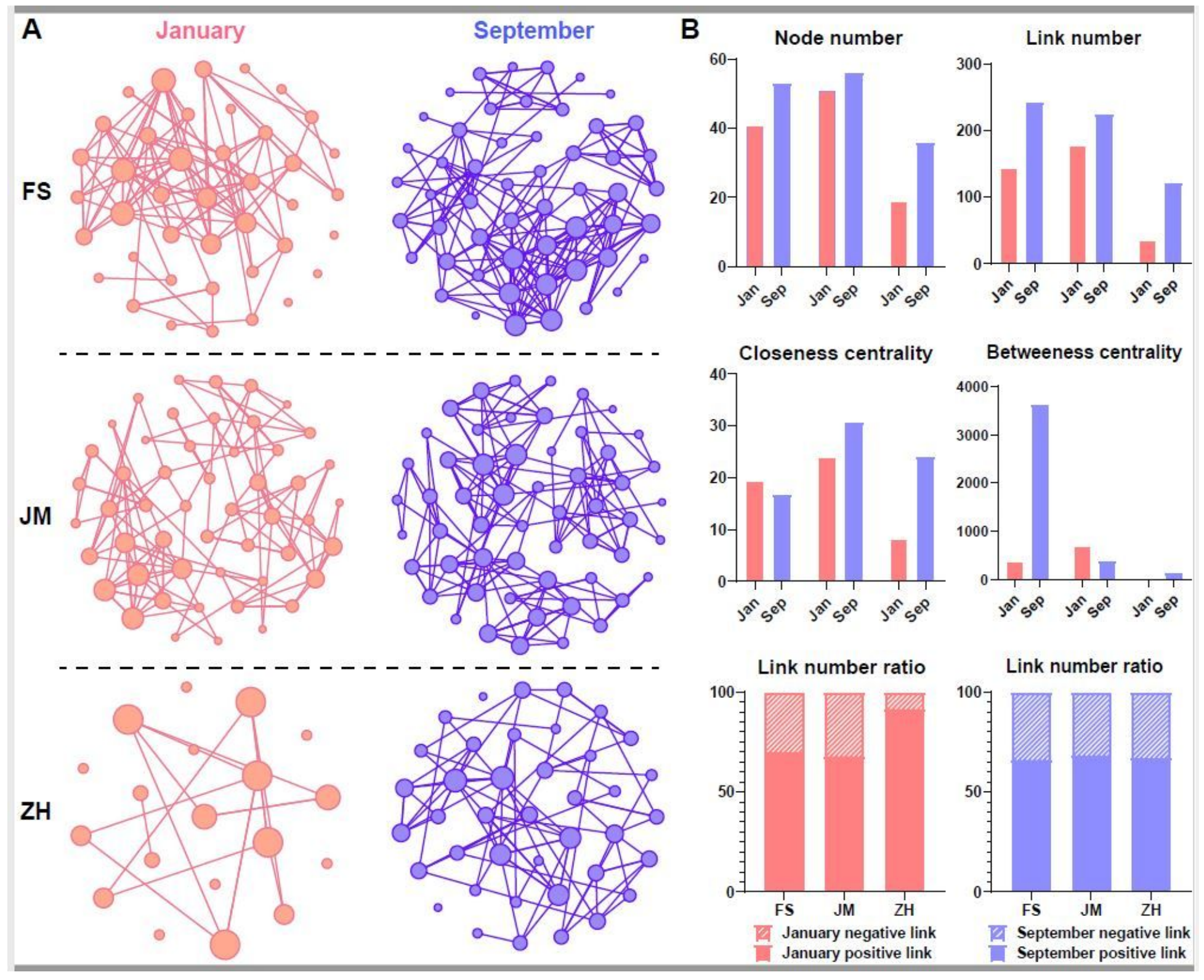

\section{Figure 4}

The co-occurrence network of the microbe-microbe at different sampled sites in January and September (A). The topological characterizations (B). The connection stands for the Spearman correlation with significance $(p<0.05)$ and high significance $(0.6<|r|<1)$. 


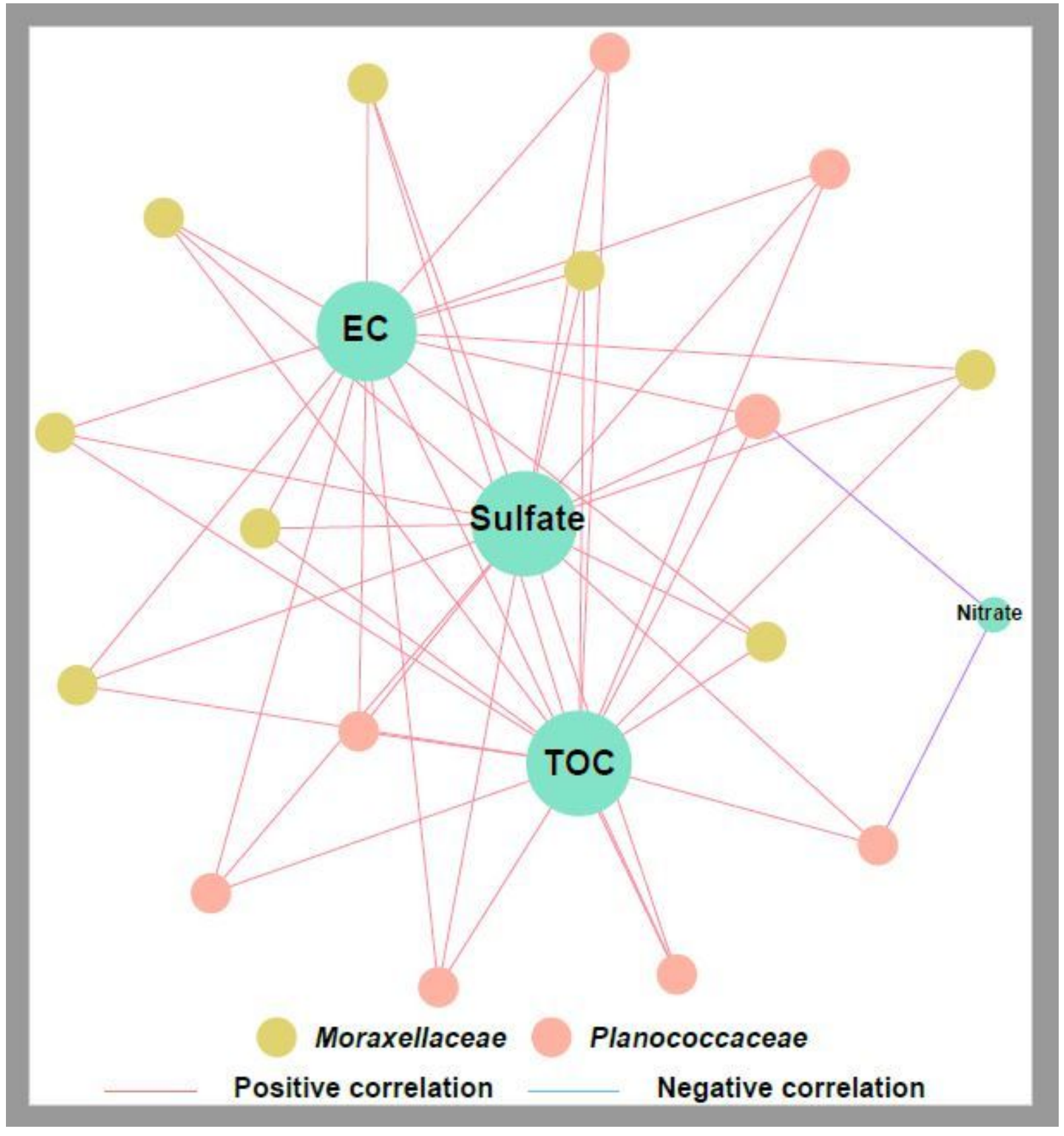

\section{Figure 5}

The co-occurrence network of the environment-microbe representing the correlations between the relative abundances of the bacterial taxa and the physicochemical parameters in $\mathrm{ZH}$. The connection stands for the Spearman correlation with significance $(p<0.05)$ and high significance $(0.6<|r|<1)$. 

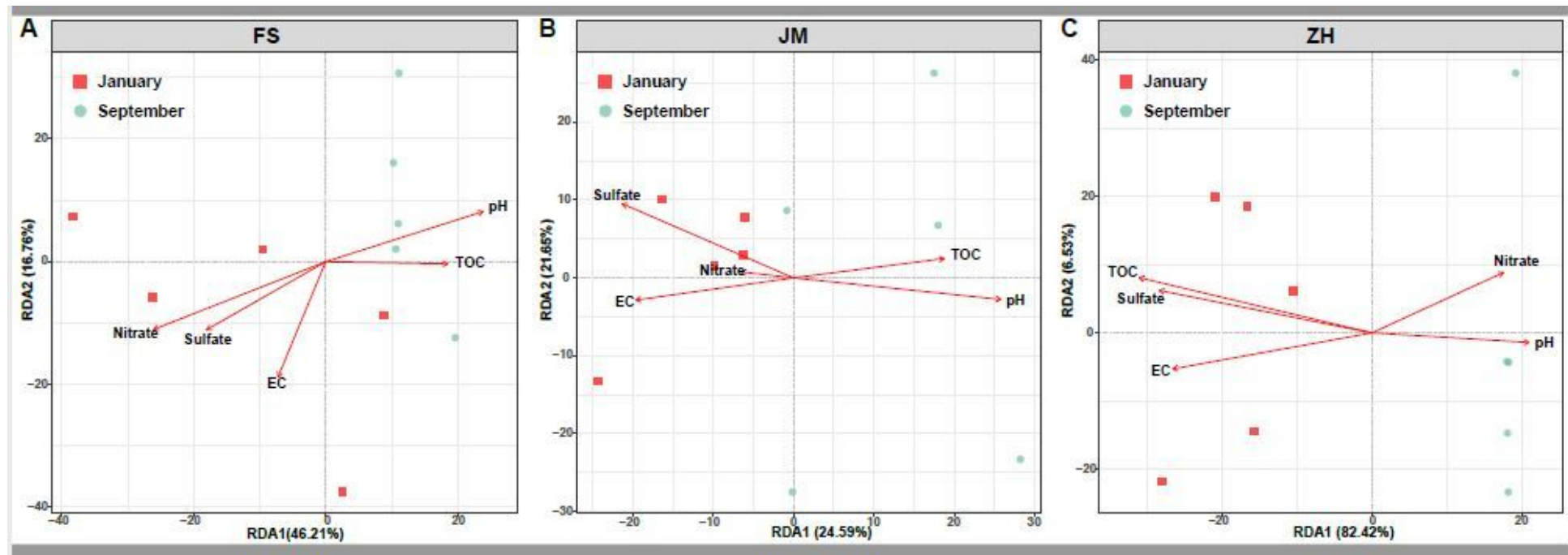

Figure 6

Redundancy analysis (RDA) demonstrating the impact of environmental factors on the bacterial communities in FS (A), JM (B), and ZH (C).

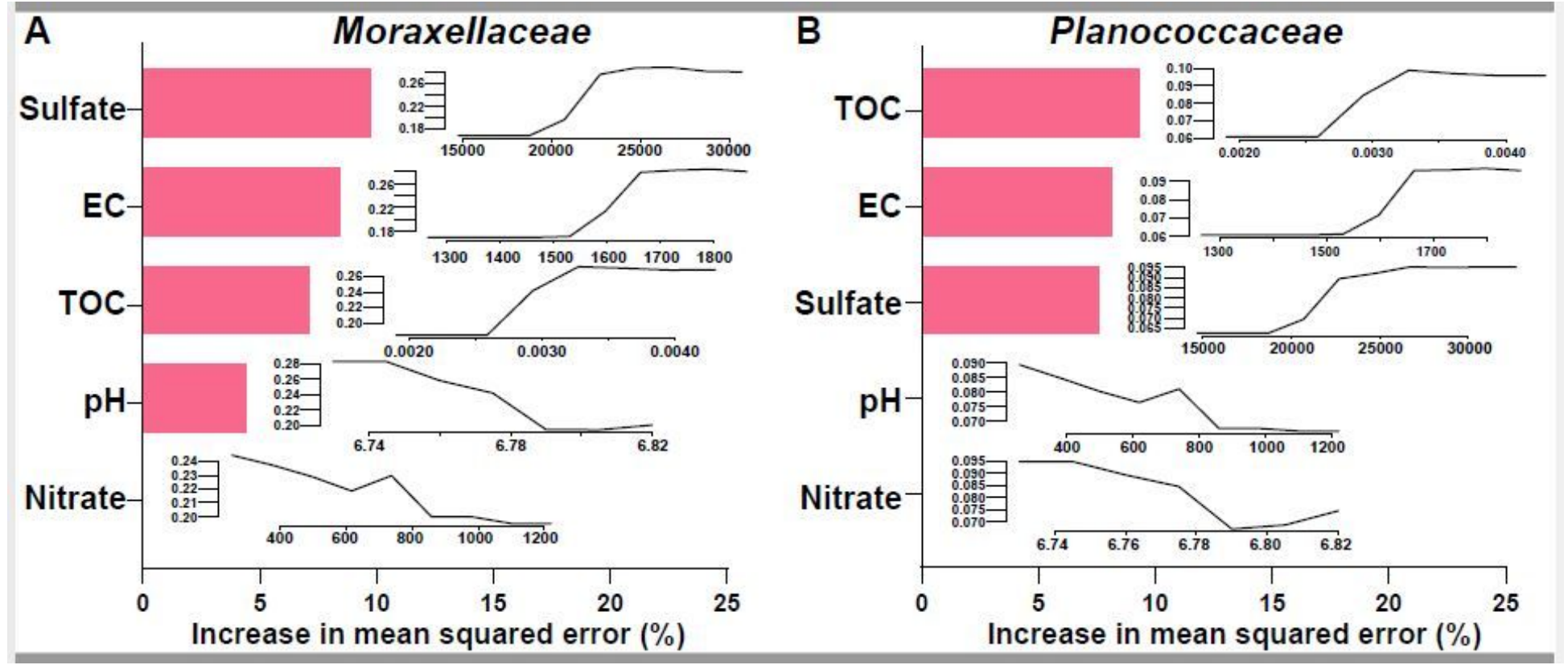

\section{Figure 7}

The random forest (RF) prediction of the relationships between the individual physicochemical parameters and the relative abundance of Moraxellaceae and Planococcaceae. The insert in the RF model represents the partial dependence plots revealing the dependencies of the relative abundance on the physicochemical parameters.

\section{Supplementary Files}

This is a list of supplementary files associated with this preprint. Click to download. 
- SupportingInformationfigure.docx

Page 24/24 